\section{Ói Nóis e Companhia do Latão: a coragem de morar com a sogra ou memória, convivio e resistência na experiência de grupos de teatro brasileiros}

Ói Nóis and Companhia do Latão: the courage of live with mother-in-law or memory, conviviality and resistance in the experience of Brazilian theater groups

Carlos Eduardo da Silva ${ }^{1}$

\section{RESUMO}

O presente artigo aborda os grupos de teatro como os genros de uma sogra nada indesejável, Mnemôsine, a deusa da memória; por isso, são núcleos importantes da memória do Teatro Brasileiro, restaurada e enriquecida constantemente. O conceito de memória é observado não apenas como a trajetória artística dos coletivos, mas como um saber adquirido que conserva as diversas experiências vivenciadas pelos membros de um grupo, seu conhecimento prático e sua maneira peculiar de fazer teatro. Além disso, a memória é tomada como uma força dinâmica, adquirida e aperfeiçoada essencialmente pelo convivio no grupo, em razão do caráter comunitário da construção dos saberes e cuja potência dependente da estabilidade da formação do coletivo articulada com estratégias de registros documentais que possam ser transmitidos às gerações subsequentes e aos novos participantes, de modo a manter vivos os princípios éticos, ideológicos e estéticos das grupalidades. As reflexões foram possíveis através da análise das trajetórias do Ói Nóis Aqui Traveiz e da Companhia do Latão. Para tanto, foram entrevistados atuantes artistas dos dois grupos. Por fim, observa-se como os grupos em questão enfrentam as pressões econômicas e políticas que são forças que tentam desagregar e destruir as memórias dessas organizações. Palavras-chave: Memória. Teatro de Grupo. Resistência. Vínculo. Convívio.
1.

Doutorando em Literatura pelo Programa de PósGraduação em Literatura da Universidade Federal de Santa Catarina, Mestre em Artes Cênicas pelo Programa de Pós-Graduação em Artes Cênicas da Universidade Federal da Bahia. ORCID: http://orcid.org/ oooo-0003-1264-3030 Contato:

cae.silva@gmail.com

Submetido em: 06/03/2017 Aceito em: 27/08/2017 


\section{Abstract}

This article deals with theater groups as sons-in-law of a kind mother-in-law, Mnemosyne, the goddess of memory, and treat them therefore as important centers of the Brazilian Theater's memory, constantly restored and enriched. The concept of memory is observed not only as the artistic trajectory of these collectives but as an acquired knowledge that preserves many experiences that they have, their practical knowledge and their peculiar way of doing theater. Moreover, memory is taken as a dynamic force, acquired and improved essentially by living together in the group, due to the community character of the construction of knowledge and whose power depends on the stability of the formation of the collective articulated with strategies of documentary records that can be transmitted to subsequent generations and new participants, in order to keep alive the ethical, ideological and aesthetic principles of groups. This reflections were possible owing to the analysis of the trajectories of Oi Nóis Aqui Traveiz and Companhia do Brass. Therefore, artists from both groups were interviewed. Finally, it is observed how the groups in question faced the economic and political pressures as forces that try to disaggregate and destroy the memories of these organizations.

Keywords: Memory; Theater Groups; Resistance; Bond; Conviviality. 
A coragem daqueles que moram com a própria sogra

PRIMEIRO FREGUÊS - A tua casa é muito frequentada por gente de teatro. MONTEIRO - Pode-se dizer que não tenho outra freguesia. Isto é uma espécie de quartel-general dos nossos atores. Entre estas paredes discutem-se peças, arrasam-se empresários, amaldiçoam-se críticos, fazem-se e desfazem-se companhias.

SEGUNDO FREGUÊS - Estão sempre a brigar uns com os outros. MONTEIRO - Isso não quer dizer nada... Vocês veem dois artistas dizerem-se horrores um do outro: parecem inimigos irreconciliáveis... mas a primeira desgraça que aconteça a um deles, abraçam-se e beijam-se. Boa gente, digo-lhes eu, boa gente, injustamente julgada.

Artur Azevedo 2

O presente artigo pretende refletir sobre o processo de transformação do teatro brasileiro nos últimos quarenta anos - uma parcela importante de sua história e práxis -, a partir da experiência, trajetória e perspectiva dos grupos de teatro, especialmente dois, que testemunharam e fizeram parte desse percurso, a saber, o gaúcho Ói Nóis Aqui Traveiz e o paulistano Companhia do Latão. O primeiro representa uma série de grupos que nasceram no final dos anos setenta, início dos oitenta, quando a ditadura militar, dando mostras de esgotamento, restituía a liberdade de associação e reunião. Mesmo assim, o Ói Nóis sofreu com o autoritarismo e a perseguição do regime de exceção vigente. A jovem Companhia do Latão, contando "somente" duas décadas, dá testemunhos da mudança no setor cultural paulistano a partir de meados da década de noventa, marcando um ressurgimento dessa modalidade de fazer teatro após um período anterior de fortes crises econômicas que devastou iniciativas dessa natureza.

Através desses grupos observa-se a operação de conceitos importantes, tais como o convívio, resistência (especialmente a política e econômica), a construção do saber continuado e, sobretudo, a manutenção da memória das comunidades onde estão sediados e do próprio teatro brasileiro. Essa análise se torna possível com a entrevista de integrantes importantes na história desses grupos, que deram seus depoimentos por ocasião de uma pesquisa promovida por este mesmo autor que deu ênfase naquela oportunidade a três aspectos das referidas associações: enquanto intermediadoras de processo de subjetivação de seus membros constituintes; matrizes artísticas cuja matéria-prima poética absorveria justamente essa mediação; e organismos dinâmicos e criativos que encontram constantemente alternativas aos diversos problemas pelos quais passam, pois con-
2.

AZEVEDO, Artur.

Mambembe, Ato Primeiro, Quadro 2, Cena I. In: Melhor Teatro Artur Azevedo. São Paulo: Global, 2008, p. 176. 
forme Trotta, "a grupalidade requer uma tomada de posição e a elaboração constante de renomadas estratégias de sobrevivência, que implicarão necessariamente lidar com a dinâmica entre a preservação e a transformação de si mesmo [...]" (TROTTA, 2011, p. 215).

Talvez resida nessa necessidade de sobrevivência tanto a grande flexibilidade e criatividade desenvolvidas nesse tipo de fazer teatral, quanto o próprio fato de artistas isolados decidirem em algum momento de suas vidas reunirem-se para formarem grupos teatrais. Pois, no coletivo encontram o mútuo apoio para as dificuldades cotidianas e melhor enfrentam as severas pressões que atingem a indesejada profissão que abraçam. Mas o fenômeno teatro de grupo não é uma jabuticaba artística, isto é, uma exclusividade ou invenção nacional, apesar disso, é um modo de realização cênica que se tornou tipicamente brasileiro, que muito bem se adaptou e excelentes frutos têm dado nas terras tupiniquins. Ainda que, na Colômbia, Argentina, França e Estados Unidos, por exemplo, essa constituição teatral apareça com vigor.

Diferentemente das companhias teatrais europeias, os grupos são independentes, desvinculados de instituições governamentais ou estabelecimentos teatrais e apresentam um caráter de resistência, na sua conduta frente às dificuldades e pressões que sofrem; de resgate, por guardarem e serem eles mesmos a memória dos tempos que testemunharam, resgatando constantemente essas reminiscências como fonte poética de suas criações; e por restaurarem um modo de fazer teatral baseado no vínculo e no convívio continuado entre seus membros, o que possibilita a aquisição de um conhecimento adquirido a partir da mediação das subjetivações nele em processo.

As companhias, por sua vez, geralmente têm um caráter estatal e empresarial associados. Talvez seja difícil compreender, pois essa realidade é mais europeia que brasileira, como por exemplo: a Royal Shakespeare Company, mantida pelo governo britânico; o Ópera Nacional de Paris; o Teatro Alla Scala, de Milão; etc. Cada uma delas têm suas atividades ligadas ao estado e a natureza da associação dos artistas é por contrato de trabalho firmado por intermédio do estatal. No que se diferem fortemente dos grupos formados em caráter quase espontâneo, por indivíduos livremente filiados e pelo descompromisso com as instituições legalmente estabelecidas, mesmo que no Brasil os dois termos sejam empregados para o mesmo fim, quase não apresentando antinomias ou diferenças significativas.

Por fim, resta uma questão: o que tem a sogra a ver com tudo isso? Não obstante a vida do artista cênico, de grupo ou não, ser cercada de dificuldades ao ponto de, às vezes, até precisar morar com a sogra, a divertida alegoria não vem ao caso por esse motivo. 
Segundo a mitologia grega, após vencer a batalha contra os Titãs, Zeus decidiu ter filhas dedicadas a cantar as glórias da sua vitória, lembrando-as eternamente. Tempos depois, nove deusas nascem, dentre elas estão Tália e Melpômene, as divindades da comédia e da tragédia respectivamente. Zeus não teve suas filhas com qualquer mortal, as musas são filhas de ninguém menos que Mnemôsine, a divindade encarregada de enfrentar os perigos do esquecimento, ou seja, a sogra do Teatro, dos artistas da cena teatral, é deusa da memória. Morar com a sogra requer coragem e resistência para responder-se as pressões são diárias, e qualquer um submetido a ela tenderia a desistir facilmente ao longo do caminho. Apesar disso, os grupos de teatro têm se mantido firmes e ativos como um segmento importante da construção do saber continuado fundado na manutenção do conhecimento no teatro brasileiro. Estes bígamos merecem, por isso, as bênçãos e o amparo da mãe de suas musas-esposas, a deusa da memória.

Teatro de Grupo ou Grupo de teatro? Generalizações e definições

Teatro de grupo é sem dúvida a forma de organização mais vigorosa e produtiva como processo de investigação, transformação e criatividade cênica. Um coletivo de trabalho é a única fonte rigorosamente penetrante e estimulante, capaz de aprofundar um projeto artístico de forma a mantê-lo permanentemente inserido na vida social e no constante confronto com a realidade, sem que perca sua capacidade de reinventar-se a si mesmo, de pesquisar linguagens inesperadas e diversificadas. PEIXOTO, 1992, p. 1

Antes de falar propriamente dos grupos em questão, surge um problema de natureza quanto a confusão de termos. Muitas vezes se usa o termo teatro de grupo como sinônimo de grupo de teatro, ou seja, tais conceitos são comumente usados para o mesmo fim. Essa confusão revela tanto uma insuficiência de parâmetros para se definir e distinguir as duas noções, quanto uma definição quantitativa, baseada em números, para fundamentar a concepção adotada. Assim, acredita-se poder identificar um grupo pela quantidade de participantes, ou tempo mínimo de existência, ou relação entre tempo de existência e produção artística, ou ainda por alguma razão matemática que comprove a estabilidade dos seus integrantes. Contudo, segundo Trotta, "parece evidente que estamos diante da necessidade de afirmar uma definição qualitativa de grupo, ainda que ela não seja quantitativamente majoritária. E quais seriam os elementos desta definição?” (2008, p. 35).

Talvez essa confusão manifesta na prática uma descontinuidade conceitual. A busca por uma definição ou pelo estabeleci- 
mento de parâmetros devem dialogar com a prática, sem promover uma elitização inútil, pois "[...] optar por uma definição estrita de grupo não consiste em excluir aqueles que ela não contempla, mas projetar uma possibilidade de futuro, por mais que hoje ela pareça utópica." (TROTTA, 2008, p. 36). Seria procurar uma definição pluralista, que não seja um sistema de validação, mas um sistema flexível que reflita a práxis teatral. Nas palavras de Cabanchik, o pluralismo "acentua a diversidade de perspectivas que nos entrega nossa experiência do mundo, sem que se julgue possível, conveniente ou necessário, um procedimento redutivo que reconduza tal experiência múltipla a uma unidade mais básica ou fundamental." (2000, p. 100, tradução nossa) ${ }^{3}$

Entretanto, para alguns pensadores do teatro, essa é uma discussão irrelevante, o problema proposto não existe e não é justificável despender esforço para encontrar uma definição que constitua um sistema de validação de uma virtual concepção que na realidade inexiste, porque todo teatro gregário, de grupo, é comunitário. O princípio desse posicionamento é a generalização do conceito de teatro de grupo. Pode-se observá-lo multiplicado na obra de alguns autores e artistas que tomam na expressão teatro de grupo ou grupo de teatro o sentido completo por uma das partes que as caracterizam: "grupo" enquanto coletivo, congregação de atores, destes com o público, críticos, etc.

Quando penso na expressão "teatro de grupo", e tão somente nela, imagino uma redundância. Teatro é, por definição, uma atividade exercida em grupo. Ainda que sob diferentes formas de organização, o aspecto coletivo se impõe na prática teatral. Haverá sempre um momento inevitável de coletividade, seja na relação com uma equipe formada por técnicos, seja no encontro com o público (ABREU, 2007, p. 58).

De saída, Picon-Vallin reafirma este posicionamento e aponta para uma noção que ignora a realidade prática das diferentes constituições e modos de se organizar a prática teatral, para centrar-se no discurso óbvio de que a reunião humana está no cerne do próprio teatro. Assim, as fronteiras, tão pálidas quanto flutuantes, do teatro de grupo, diluem-se por completo, pois segundo a autora:

[...] a primeira coisa que vem à mente é que o "teatro de grupo" é uma tautologia das mais estranhas - todo teatro deveria ser "de grupo", uma vez que a definição da palavra grupo, se consultarmos um dicionário, é a seguinte: "Reunião de seres formando um conjunto" [...] Segundo essa definição, o teatro é certa e necessariamente praticado por um grupo de artistas e técnicos, mesmo no caso de um espetáculo solo. (PICON-VALLIN, 2008, p. 82).
3.

"acentúa la diversidad de perspectivas que nos entrega nuestra experiencia del mundo, sin que se juzgue posible, conveniente o necesario, un procedimiento reductivo que reconduzca tal experiencia múltiple a uma unidad más básica o fundamental" 
Porém, a pesquisadora tenta em seguida construir uma definição que ultrapasse a questão meramente etimológica e observa outros parâmetros relacionados ao tema, como o aspecto da liderança presente na comunidade reunida; as questões de profissionalização do coletivo; a pesquisa estética e de linguagem artística continuada; e o vínculo entre os indivíduos envolvidos. Com isso a autora relaciona no seu conceito do que seja um grupo a partir da congregação de indivíduos com vínculos afetivos entre si em torno de um projeto estético, com ou sem liderança e dotados ou não de preocupação profissional.

[...] o teatro de grupo pode ser definido, quer se atribua explicitamente ou não tal denominação, como uma comunidade artística reunida, no mais das vezes, em torno a um ou mais líderes, empenhados num mesmo projeto. Ele pode ser amador, semiprofissional ou profissional, e pode escolher, conforme seu status (que pode evoluir), a relação com os outros, a pesquisa artística, o impacto na sociedade, a qualidade perturbadora da criação, até mesmo a refundação do teatro. Porém, as relações de confiança, entendimento, cumplicidade, compartilhamento, que dão fundamento ao grupo enquanto tal, têm seu reverso: o voltar-se para dentro, para o trabalho de pesquisa, devido às dificuldades a serem superadas e à intensidade do trabalho no decorrer do processo de ensaios (PICONVALLIN, 2008, p. 88).

Menos titubeante, para Abreu (2008) o sentido de grupo de teatro busca apontar uma definição que contemple com precisão os elementos qualitativos dessa forma teatral e que possam melhor refletir a realidade dos grupos. Essa realidade é composta por um projeto estético continuado e, por isso, extenso no tempo, que ultrapassa as fronteiras de uma montagem isolada, que se constrói e aperfeiçoa através do processo de trabalho do coletivo de forma cumulativa, formando seu patrimônio cultural. Um grupo de teatro é, antes de tudo, o formador de um patrimônio cultural baseado na sua experiência coletiva continuada.

[...] um grupo de teatro, na lógica que estamos organizando, não é o mesmo que um agrupamento de artistas que se reúnem para fazer um trabalho determinado. $O$ que marca a existência de um grupo - ao menos no sentido que interessa aqui - é uma experiência comum colocada em perspectiva. Não se trata pontualmente de um evento artístico, ainda que um evento, um espetáculo, por exemplo, possa estar nos planos do grupo, como, de fato, quase sempre está. Trata-se, antes, de um projeto estético, de um conjunto de práticas marcadas pelo procedimento processual e em atividade continuada, pela experimentação e pela especulação criativa, que pode até mesmo se desdobrar ou alimentar desejos de intervenção de outra ordem que não a estritamente artística (ABREU, 2008, p. 92). 
A despeito, da contraditória posição da autora francesa, para o ator e diretor Neto, que é profundamente ligado ao universo da prática teatral, a questão é abordada sem subterfúgios retóricos. Com a experiência de quem convive e vivencia cotidianamente a práxis da sua arte, conhece a especificidade e profundidade do projeto estético, do procedimento processual continuado, das implicações conceituais que se desdobram das especulações criativas presentes na proposta constitutiva de teatros de grupo; esse artista aborda o tema com uma clareza tal que parece por vezes simplificá-lo, sem que isso signifique um prejuízo à abordagem apresentada, aliás sua resposta enseja profundas reflexões sobre o que envolve fazer, pensar e conceituar o teatro de grupo e o grupo de teatro:

O primeiro [teatro de grupo], no meu entender, é aquilo que resulta do trabalho contínuo de um grupo de teatro, que contempla outras atividades para além da cena, artística ou não, que fomentem as discussões estéticas, éticas e política do fazer teatral. O segundo, um agrupamento de atores - circunstancial ou de forma mais duradoura - para fazer teatro. Grupos de teatro podem ou não ter como resultado um teatro de grupo (NETO, 2007, p. 34).

Nesse caso, surge a diferenciação pelo modo e pela forma, teatro de grupo seria um modo de trabalho coletivo; fundado sobre motivações e crenças artístico-estéticas; formado a partir da constituição e aprofundamento do vínculo entre seus integrantes diretos, estabelecido no convívio e no acontecimento teatral; e apoiado num sem número de métodos e processos criativos coletivos ou colaborativos ${ }^{4}$. Cabe lembrar a distinção de que criação coletiva é toda aquela que envolva, independentemente de hierarquias, mais de um indivíduo, enquanto processos colaborativos, demandam o compartilhamento do poder decisório sobre as soluções criativas a serem adotadas e consequente flexibilização hierárquica no coletivo. Por sua vez, grupo de teatro é uma forma de organização ou institucionalização dessa prática.

Grupo como resultado qualitativo do vínculo, convívio e acontecimento teatral ${ }^{5}$

A força teatral de um povo não se mede apenas pela obra de seus artistas como também, e especialmente, pelos seus convívios.

(JORGE DUBATTI)

O psicanalista suíço-argentino Henrique Pichon-Rivière dedicou parte de sua carreira, e consequente obra, a investigar e refletir sobre as relações interpessoais, os vínculos, grupos e
4.

Para o conceito de processo colaborativo, vide Fischer (2010) e Silva (2008).

5.

Para Dubatti, "acontecimento teatral" refere-se à "apresentação teatral", ou seja, é quando o teatro acontece, antes é ensaio, depois é memória. 
processos delas provenientes. O vínculo pode ser explicado da seguinte forma: o indivíduo desenvolve um mecanismo para internalizar na sua psique os objetos existentes no mundo. O vínculo é essa estrutura relacional, cujo objetivo é o aprendizado, internalizar para conhecer.

Relação de objeto é a estrutura interna do vínculo. [...] É uma estrutura dinâmica em contínuo movimento. [...] Podemos definir o vínculo como uma relação particular com o objeto. Essa relação particular tem como consequência uma conduta mais ou menos fixa com esse objeto [...] (PICHON-RIVIÈRE, 2007, p. 17).

Essa estrutura relacional ocorre em dois níveis, no nível psíquico, referente aos processos mentais do indivíduo, e no nível social, a partir de como o indivíduo vai expressar pelo seu comportamento essa relação interior. O vínculo se aprofunda e aperfeiçoa a partir do convívio possibilitado por acontecimentos que estimulem encontros. Especificamente, o "acontecimento teatral" é o objetivo primeiro do fazer teatral com delimitação temporal (horário para começar e acabar), estruturação de encontros entre aqueles que atendem ao evento, e articulação das suas relações de produção e recepção de poiesis.

Nesse sentido, o acontecimento congrega poiesis, presença $e$ expectação. Já que a presença produz "convívio", então esse acontecimento instaura grupos que, em razão do seu caráter determinado no tempo, são efêmeros. Assim, esses grupos transitórios operam no espaço-tempo instaurado, criando e compartilhando poesia, para se extinguirem em seguida. A diferença de um grupo instaurado no "acontecimento teatral" para outros grupos mais estáveis, no nível mais óbvio, está na durabilidade que não constitui vínculos, comparativamente aos grupos estáveis que o fazem.

O "acontecimento teatral" reproduz microscopicamente na sua duração, mas não menos na intensidade, as tensões, conflitos e crises como em qualquer grupo. A presentificação dessa relação é o próprio convívio. Assim, convívio é um compartilhamento presencial do fenômeno de experiência coletiva, ou, simplesmente: estar junto. "O ponto de partida do teatro é, então a instituição ancestral do convívio: a reunião, o encontro de um grupo de homens num centro territorial, num ponto do espaço e do tempo, ou seja, nos termos de Dupont, a 'cultura vivente do mundo antigo' "' (DUBATTI, 2007, p. 47, tradução nossa) ${ }^{6}$.

O convívio é uma reunião sem obrigatoriedade de continuação, isto é, os partícipes podem conviver sem reencontrarem-se, sem estabelecerem um hábito convivial. Porém, empreender a edificação e fortalecimento dos vínculos até se chegar num modelo
"El punto de partida del teatro es, entonces, la institución ancestral del convivio: la reunión, el encuentro de un grupo de hombres en un centro territorial, en un punto del espacio y del tiempo, es decir, en términos de Dupont, la 'cultura vivente del mundo antiguo'." 
complexo de relação interpessoal como o existente num grupo de teatro, demanda a necessidade do hábito convivial, da rotina de encontros ou reuniões.

O convívio implica estar com o(s) outro(s), mas também consigo mesmo, dialética do eu-tu, do sair-se de si ao encontro com o outro/ consigo mesmo. Importa o diálogo das presenças a conversação: o reconhecimento do outro e de si próprio, afetar e deixar-se afetar no encontro, gerando uma suspensão da solidão e do isolamento (DUBATTI, 2007, p. 47, tradução nossa)7.

Dubatti identifica três tipos de convívios: o convívio pré-teatral, o teatral e o pós-teatral. O primeiro tipo é onde as relações interpessoais se localizam e entram em fricção, operacionalizando as tarefas do grupo; onde os processos de aprendizado e treinamento ocorrem com maior disposição de tempo; onde os encontros acontecem e os ensaios criam, aperfeiçoam e simulam o acontecimento teatral. A relação de estabilidade entre o aperfeiçoamento do vínculo e a regularidade do convívio resultam na consolidação de uma estrutura que resulta numa equipe de trabalho, num grupo:

[...] no extremo da estabilidade estão os conjuntos fechados cujos integrantes são fixos e não há permeabilidade ou movimento em sua constituição; no extremo da renovação estão os grupos abertos, cuja constituição muda a cada espetáculo, permanecendo apenas um núcleo central (TROTTA, 2011, p. 220).

O vínculo está condicionado a questões afetivas e ideológicas, econômicas, políticas relacionadas ao coletivo. Por outro lado, os elencos provisórios montados em razão de determinadas obras teatrais configuram um modo de grupo temporário, onde o seu convívio não é marcado necessariamente pela coerência das mesmas questões. O segundo tipo de convívio é o teatral, que determina o fator de presença aurática nos acontecimentos teatrais e estabelece a experiência real do fenômeno; é produzido em função das práticas teatrais - tem algumas características essenciais: a presença física, consequentemente, a intransferibilidade, e em razão da alternância solidão-encontro, efemeridade. A característica presencial é preconizada da seguinte maneira por Dubatti:

Reunião de auras, o convívio teatral estende ao máximo o conceito benjaminiano de arte aurática. $O$ encontro de auras não é perdurável, permanece o que é fruto do convívio: por consequência, é também império do efêmero, de uma experiência histórica que acontece e imediatamente se dissipa, para logo tornar-se irrecuperável (2007, p. 62, tradução nossa) ${ }^{8}$.
7.

"el convivio implica estar con el otro/los otros, pero también con uno mismo, dialéctica del salirse de sí al encuentro con el otro/ con uno mismo. Importa el diálogo de las presencias, la conversación: el reconocimiento del otro y del uno mismo, afectary dejarse afectar en el encuentro, generando una suspensión de la soledad y

el aislamiento."

8.

"Reunión de auras, el convivio teatral extiende al máximo el concepto benjaminiano de arte aurático. El encuentro de auras no es perdurable, permanece lo que el convivio: em consecuencia, es también imperio de lo efímero, de una experiencia histórica que sucede e inmediatamente se desvanece, para luego tornarse irrecuperable." 
Essa visão de Dubatti não se harmoniza com noções contemporâneas de virtualidade atingidas pelas mais modernas tecnologias e circunscreve um teatro vivo e ao vivo. Para o autor argentino, é inviável experimentar ou atender a experiência convivial do teatro de maneira virtual ou por terceiros. "O acontecimento convivial é experiência vital intransferível (não comunicável a quem não assiste ao convívio, não se pode 〈contar〉 na sua vastidão, nem reconstruir ou restaurar), deve-se vivê-lo." (DUBATTI, 2007, p. 63, tradução nossa) ${ }^{9}$

O último tipo de convívio é o pós-teatral, que se refere a formação de qualquer grupo, independentemente de duração e do local de reunião, necessariamente motivados e estimulados por um acontecimento teatral. Trata-se, portanto, dos grupos efêmeros que, após uma apresentação ou experiência teatral, se reúnem na escadaria da saída do teatro, num bar, num restaurante, na praça, etc., para falarem sobre a experiência estética teatral fruída minutos ou horas antes.

A memória de um grupo reside não apenas em registros e materiais documentados arquivados, mas sobretudo na reminiscência de seu convívio que reparte e fragmenta a memória do coletivo na vivência e sob a perspectiva de cada envolvido. Razão pela qual o maior patrimônio de cada grupo, inclusive os teatrais, são seus integrantes. Neles reside a mística de Mnemôsine.

\section{Ói Nóis Aqui Traveiz e Companhia do Latão! Memórias em trânsito}

O Ói Nóis foi fundado no final dos anos setenta, por um grupo de artistas com forte espírito artístico transgressor e inovador. O grupo apresenta uma característica estética questionadora e que "ousa ir além da resistência", é poroso ao seu tempo e sensível às questões em voga no seu entorno. O corpo de artistas é móvel e o coletivo é relativamente aberto, isto é, após ingressarem nas oficinas os artistas podem participar do grupo, já sua constituição jurídica e seu quadro social não é tão aberto e móvel assim. O coletivo gaúcho tenta ocupar espaços alternativos e realiza montagens ousadas através do método colaborativo e, mesmo quando parte de um texto pronto, imprime a característica de todos os envolvidos no processo na obra final.

O Ói Nóis é fruto de um período, é estar sempre atento ao que se passa aqui, agora. Isso faz com que o Ói Nóis esteja o tempo inteiro dialogando com essas forças que se transformam porque na verdade não tivemos a sorte de ver simplesmente essas forças desaparecerem, elas mudaram de rosto, de roupa, mas elas seguem por aí, por exemplo, participamos dos protestos, em julho de dois mil
"El acontecimiento convivial es experiência vital intransferible (no comunicable a quien no asiste al convivio, no se puede 'contar' en su vastedad, ni reconstruir o restaurar), hay que vivirlo." 
e treze, e levamos bomba de gás na cara, apesar de estarmos do lado de gente muito velha, carregando cartazes, cantando canções lindas na rua, sentindo uma força cívica maravilhosa, todos juntos e, de repente, somos agredido pela polícia (FARIAS $\left.{ }^{10}, 2014\right)$.

Pelo seu grau de porosidade, do quanto deixa-se reverberar pelas questões mais em voga no contexto social em que esteja inserido, o Ói Nóis tende a ser uma fonte de memória não apenas dos seus processos artísticos, mas também da sociedade como um todo. $\mathrm{Na}$ época, em que o regime militar ainda vigorava mesmo que em declínio, o grupo gaúcho enfrentou severa perseguição, respondendo a esse contexto estressante com apaixonadas discussões, rachas e logros artísticos viscerais.

Além disso, o Ói Nois foi marcado pelo processo de gentrificação que forçou o despejo do grupo. Esse processo mobilizou movimentos de apoio social e provocou desagregação interna com saída de importantes participantes do grupo até então. Para Flores, o processo de especulação imobiliária fragilizou o grupo ocasionando um desmantelamento. De acordo com Paulo Flores, essa foi a causa da pior crise da história do grupo:

O que afetou mesmo durante a minha trajetória no grupo foi quando as pessoas, de um momento para outro em cima dos seus interesses pessoais, traíram a ideia do grupo. Nesses trinta e seis anos o que me afetou profundamente foi no momento que o Ói Nóis estava em confronto com a prefeitura [...] e várias pessoas do grupo saíram, deixaram o grupo, e logo em seguida foram contratadas para trabalhar na prefeitura. [...] eu não esperava porque sempre acredito que as pessoas estão envolvidas no Ói Nóis pelas questões ideológicas, nesse trabalho coletivo, ideias políticas, próximas... e esse foi um momento de saber que as pessoas estão saindo porque elas estão sendo contratadas, estão fazendo críticas ao procedimento do grupo sem terem proposto mudanças antes [...] Isso, para $\mathrm{mim}$, foi a grande crise do grupo porque aí saiu essa pessoa e com o respaldo de mais três, quatro ou cinco pessoas (Paulo Flores, 2014).

Pela natureza das relações do trabalho artístico, constante pressão e eventuais frustrações envolvidas, as crises estão presentes cotidianamente e servem, sobretudo, como registros de processos, marcando a memória de determinados eventos, associando acontecimentos. A combinação da experiência de acontecimentos comuns (ainda que sob perspectivas distintas) reforça de alguma maneira o vínculo dos envolvidos, assim, a memória compartilhada aprofunda os laços dos membros de um grupo, traumas e vitórias são lastros de uma trajetória presente na dimensão afetiva dessas pessoas.
10.

Todas as entrevistas dos membros do grupo Ói Nóis Aqui Traveiz e da Companhia do Latão, citadas ao longo deste artigo, foram dadas em 2014 e publicadas em 2015 por ocasião da dissertação de mestrado deste autor. Disponíveis na íntegra em: SILVA, Carlos Eduardo da. A dinâmica das relações interpessoais em teatro de grupo: pressões externas e tensões internas na experiência de coletivos teatrais brasileiros. Mestrado em Artes Cênicas. Bahia: Escola de Teatro, Universidade Federal da Bahia, Salvador, 2015. 
A Cia. do Latão faz parte de uma geração de grupos de teatro recente no movimento de teatro de grupo brasileiro. Formaram-se após a crise econômica da década de oitenta e do governo Collor, que dizimou iniciativas do gênero, e correspondem ao ressurgimento cultural estimulado pelas primeiras leis de fomento à cultura. Curiosamente, esses artistas encontraram-se nas ou por intermédio das universidades. Cursos de graduação em Artes Cênicas são um fenômeno recente, datam de metade do século $\mathrm{XX}$, as pós-graduações, sobretudo, advém dos anos oitenta. E a companhia paulista é um exemplo de coletivo nascido a partir do ambiente acadêmico.

Talvez por isso, esse grupo tenha uma pesquisa estética e de linguagem que tenta unir teoria e prática não como consequência dos seus projetos artísticos, mas enquanto mote inicial dos mesmos. O projeto estético, porém, não está acima dos vínculos e relações conviviais, cuja memória também é marcada pela "crise nossa de cada dia". Mas, Sérgio de Carvalho, que é o diretor do Latão, defende a importância do papel do diretor na criação das circunstâncias para que o indivíduo sinta-se acolhido e à vontade para se expressar e criar. Esses momentos sim, são relevantes na memória do grupo, avalia o diretor. $\mathrm{O}$ artista deve agir com liberdade para o erro e para o acerto, para realizar experimentos e explorações suas potencialidades estéticas em vez de apenas reproduzir em cena e no processo criativo as mesmas pressões mercantis que sofre fora dela.

[o conflito] aparece o tempo todo, o difícil é criar um ambiente em que as pessoas respeitem o trabalho dos outros, em que elas tenham um interesse pelo trabalho dos outros, em assistir a cena dos outros, isso é mais difícil... coisa rara nesse nosso trabalho é ver um ator de fato entregue ao trabalho dele, assistindo um cena com prazer, criando... isso não é a regra, é a exceção, a regra é o ator estar preocupado com a ceninha dele, é o ator vir e dar um pitaco na cena do outro de modo que favoreça a cena dele (Sérgio de Carvalho, 2014).

A memória do grupo resistindo às pressões política e econômica

A pressão das forças políticas e econômicas tensionam o processo de constituição e manutenção da memória dos grupos na medida que provocam a desestabilidade de seus membros, a saída deintegrantes e a constante mudança no corpo de artistas, que se não for bem administrada, pode resultar na perda de saberes e experiências do coletivo. A coerente conciliação entre pressão econômica e posição ideológica de um grupo são essenciais para a consolidação de seu projeto e da própria estabilidade do seu quadro de artistas. Do contrário, a tensão provoca a desagregação do coletivo e eventualmente o resultado prático é uma 
descontinuidade na formação humana do grupo. Sobre a estabilidade na formação reflete Carreira:

A duração dos projetos e a manutenção de equipes estáveis podem ser indicadas como características que contribuem para estruturar o espaço simbólico do trabalho que tem o grupo como eixo. Isso não impede que muitos dos grupos [...] sofram constantemente com o fluxo de integrantes [...]. Assim, podemos ver grupos que têm uma longa história assentada em um núcleo permanente reduzido, ao redor do qual circulam participantes que periodicamente se renovam. Esse núcleo que permanece constitui, então o elo entre os diferentes momentos do grupo, o que garante a própria noção de continuidade no trabalho (2007, p. 10).

O Ói Nóis foi fundado em 1979, apesar de sua formação ter sido articulada desde anos anteriores. Por isso, o grupo sofreu a pressão direta do regime militar que ditou o Brasil (1964-1985). O período do autoritarismo teve graves consequências para os movimentos organizados da sociedade civil, dos quais o movimento de teatro de grupos:

[...] o país atravessa a repressão ditatorial, com o desmantelamento das universidades, dos movimentos sindicais, dos focos de resistência da sociedade, com o assassinato de operários, professores, jornalistas e militantes nos porões da tortura, e com a asfixia das potencialidades criativas [...] (FERNANDES, 2011, p. 68).

Três palavras resumem esse período para os grupos teatrais brasileiros: resistência, repressão e clandestinidade. Resistência contra a censura e as dificuldades de financiamento dos projetos artísticos; opressão e perseguição aos artistas independentes e reunidos em grupo contra o regime; e clandestinidade na realização e apresentação dos trabalhos. Um dos fundadores do Ói Nóis, o dramaturgo Júlio Zanotta, revela um pouco das suas memórias sobre aquele jovem grupo de atores que viveu os primeiros anos do coletivo gaúcho sob o véu da ditadura militar:

[...] o período da ditadura, para quem viveu, tem um caráter subjetivo que é difícil de explicar, é uma espécie de medo coletivo provocado pelas forças da repressão, você tinha medo até de escutar uma música dentro de casa, você policiava o que estava dizendo, você estava constantemente na defensiva, antes de atravessar uma rua você olhava para os lados escuros, você não sabia se seria abordado, espancado, você estava num bar tinha uma batida policial e você não sabia se essa batida era contra você e seu grupo ou se era uma coincidência... enfim, esse medo coletivo, instaurado na sociedade, ele embargava, ele tolhia as ações artísticas, a expressividade, quando você estava na oposição. E, ao mesmo tempo em que você se sentia perseguido e caçado, você recebia apoios solidários de muitos setores em pequenos gestos [...] (ZANOTTA, 2014). 
Ante uma situação tão grave, naturalmente as relações interpessoais dos grupos internalizam essa pressão nas estruturas internas através de tensões de variadas ordens. Dessa forma, a memória sedimenta-se pelos fatos de exceção. Questionado sobre como ficavam as relações do grupo, assim respondeu Júlio Zanotta:

[...] isso esfacelou o grupo até, pelo contrário [não agregou]. Essa pressão externa contribuiu ainda mais para uma espécie de debandada. [...] eu acho que o Ói Nóis só não foi mais reprimido violentamente porque se tratava de um caso público, eram atores, havia jornalistas, eu era jornalista na época, tinha a cobertura da imprensa, então aquilo nos protegeu um pouco. Já durante os ensaios, o Paulo Flores, a Silvia Veluza e o Rafael Baião foram presos [...] Nós recebemos no Ói Nóis Aqui Traveiz, uma ação orquestrada dos órgãos de repressão, que ia desde o departamento de censura da polícia federal, até o serviço de informação das forças armadas, aí entrou DOPS, entrou DOI-CODI [...] (2014).

O esfacelamento do grupo era consequência de uma pressão que forçava muitos artistas ao exílio, como o próprio Zanotta, à clandestinidade ou à prisão injustificada. Além disso, o estado de tensão alterado produzia embates e rupturas inflamadas entre os integrantes do Ói Nóis. Por outro lado, os fundamentos ideológicos do grupo gaúcho eram fortalecidos e reforçavam a postura de resistência, questionamento estético e da própria ordem social estabelecida. Essas posições combativas e corajosas já estavam muito claras nos primeiros trabalhos do grupo, um comportamento que não se perdeu com o passar dos anos, conforme testemunha Tânia Farias: "é um aspecto fundamental do trabalho, até porque o Ói Nóis não se priva de se colocar politicamente. O Ói Nóis é um grupo que sempre tem uma opinião, não vai estar neutro porque vai ser mais conveniente" (2014).

Diferentemente, a Companhia do Latão não viveu uma experiência política dessa ordem. O grupo paulista adota uma postura ideológica iminentemente marxista e contrária ao sistema econômico hegemônico. O ponto de encontro entre a memória desses dois grupos parece ocorrer no depoimento de Tânia Farias, do grupo gaúcho, para quem os tempos se renovaram, a democracia foi restabelecida, mas as forças de repressão do antigo regime também se transformaram para continuar existindo através de outras formas de autoritarismo e controle. Segundo as palavras de Tânia Farias: "guardadas as devidas proporções, o fato de podermos estar falando aqui, evidente que nós avançamos em várias questões, não estou dizendo que é tudo igual, estou dizendo que existe um opressor que continua aí, ele se transformou para continuar existindo". (2014) O mesmo concentrador do capital 
contra o qual luta a Companhia do Latão, age ocasionando o processo de gentrificação que afetou o Ói Nóis.

A pressão econômica, por sua vez, vem da necessidade comum e imediata de subsistência. $O$ artista cênico convive permanentemente com o conflito econômico, de acordo com Ney Piacentini, "[...] se fala que você precisa ganhar o dinheiro, precisa ter uma vida com recursos e materiais de tal ordem, etc., etc. A vida adulta às vezes envolve família, filhos... e como se manter num grupo de teatro num contexto desse?" (2014). Os indivíduos precisam de recursos financeiros para a manutenção de suas vidas (moradia, saúde, entretenimento, etc.) e os grupos necessitam arcar com as despesas dos projetos que almejam realizar. Um grupo nunca será estável se criticar um sistema econômico ao mesmo tempo que seus integrantes têm, em suas vidas pessoais, os sonhos estabelecidos por esse mesmo sistema: o consumo, a acumulação de capital, a exploração da mão de obra etc.

O Ói Nóis, ao longo de inúmeras crises e diásporas, percebeu-se diante da necessidade de lidar com o constante fluxo de participantes. Marta Hass relata, "esse estado de constante renovação sempre fez parte do que o ói Nóis é [...]”. (2014) O grupo atribui a si próprio um caráter de movimento e não de grupo estático, conforme Paulo Flores, "talvez o Ói Nóis tenha mais uma característica de movimento" (2014). A solução que esse grupo encontra para não perder sua memória, perpetuar seu conhecimento e transmiti-lo de geração em geração é através das oficinas. No Ói Nóis um participante não entra, mas é formado, o que explica, de certo modo, a intensidade da manutenção do sistema de crenças e valores desse grupo.

[No Ói Nóis] as pessoas que acabam entrando no grupo participaram de oficinas antes e isso significa que as pessoas têm uma afinidade com o trabalho do grupo e com a forma com que o grupo trabalha. Não acontece de uma pessoa começar a trabalhar no grupo sem saber como é a própria dinâmica do nosso trabalho, nas próprias oficinas isso já vai acontecer e se criam afinidades, costumamos até dizer que não é o grupo que escolhe as pessoas, mas são as pessoas que escolhem o grupo porque é um trabalho muito por afinidade (HASS, 2014).

Além da formação de novos artistas para o grupo, que resulta na manutenção ideológica, ética e artística do coletivo, esse projeto pedagógico retorna à sociedade um incontável número de artistas que seguem carreira em outras grupalidades, ou mesmo de maneira solo, fazendo do Ói Nóis não apenas uma incubadora de si mesmo, mas de outros grupos e artistas que venham a surgir a partir dele. 
[...] tem muitos atores, muitos grupos em Porto Alegre que se formaram a partir do trabalho do Ói Nóis, pessoas que se conheceram em oficinas ou dentro do próprio grupo, trabalharam um tempo com o grupo e foram criar outro grupo e isso é muito bonito também. (HASS, 2014).

Os grupos vêm adotando uma estrutura produtiva funcional que exige a sua estruturação e especialização, naquilo que o sistema econômico chama de profissionalização. Essa adequação serve ao mercado de projetos culturais, de busca por patrocínios e subsídios de manutenção, a partir dos quais os grupos vão materializar seus trabalhos. O desafio para esses coletivos é não deixar suas relações criativas serem contaminadas pelas relações mercadológicas produtivas. As relações de criação, por seu turno, não obedecem às mesmas lógicas da economia, pois mesmo com a adoção das funções produtivas, a especialização em papéis definidos e hierarquização numa estrutura, as relações de criação podem continuar sujeitas a métodos horizontais e participativos, como na criação coletiva ou no processo colaborativo, por exemplo.

Segundo Sérgio de Carvalho, "um grupo de teatro como o nosso não se pensa como uma unidade empresarial, mas como uma formação de outro tipo, mais livre, não orientada por critérios mercantis". (2014) Conforme Paulo Flores, "É uma questão ideológica bem clara de acreditar em alguns tipos de valores que se contrapõem, são bem distintos do que a sociedade coloca para nós como prática de vida ou possibilidade de sobrevivência, do pensamento dominante que está aî" (2014).

A postura de resistência à estrutura mercantilizada não significa que esses coletivos sejam contra o fomento e o patrocínio, desde que não seja um financiamento associado a questões que confrontem os princípios ideológicos eleitos pelo grupo. Entretanto, essa escolha parte de uma decisão baseada na relação ideológica que o grupo mantém com a sociedade, do quão fortemente sua memória, os valores éticos e estéticos que nela são preservados, mantêm-se vivos e de como concilia interiorização das pressões produtivas mercantis no seu processo de trabalho. Mesmo quando o grupo decide afrouxar seus vínculos laborais e refutar o modelo produtivo funcional, a pressão econômica continua agindo sobre seus projetos artísticos. A sua estrutura produtiva não tem a obrigação de captar recursos constantemente para o pagamento de salários, mas continua tendo que prover o correspondente financeiro necessário para a realização dos projetos artísticos. O Latão busca internalizar conscientemente essas forças econômicas e através do seu projeto ideológico tenta manter o grupo unido mesmo em circunstâncias monetárias nem sempre favoráveis. 
[...] a questão é essa, ao mesmo tempo um grupo de teatro está na periferia do mercado das artes e vai ter que se sustentar em algum nível. Acho que a questão de consenso difícil para um grupo de teatro é, em que medida a forma-mercadoria e as pressões do mercado vão ser internalizadas ou não por esse grupo? (CARVALHO, 2014).

Como alternativa, os grupos optam por modelos produtivos próprios que refletem seus sistemas de valores e reverberam no seu método de trabalho. Assim como a pressão econômica é permanente, também a sua interiorização é constante, seja pelo aperfeiçoamento do modelo produtivo funcional; seja pela resistência e melhoramento do modelo produtivo alternativo; ou, ainda, nos modelos intermediários, ou mistos. De qualquer forma, não se pode qualificar a eficiência artística, o critério ideológico de uma estrutura em comparação com a outra, tampouco apontar um modelo como sendo mais ou menos crítico da sociedade que se insere. Em verdade, não se trata de estabelecer oposições simples nem concorrência de modelos, mas apresentar escolhas que melhor representam o pensamento dos coletivos em questão e que tenham por maior objetivo fortalecê-los para lidar com a pressão econômica. Desse modo, as relações interpessoais vão transitar entre as relações produtivas - dos modelos funcionais ou alternativos - e as relações criativas.

Porém, independentemente de como a pressão econômica se internalize, uma consequência possível a se evitar está em tornar o indivíduo mais competitivo e ávido por ganhos monetários, poder, ou ativar mecanismos de frustração profissional quando isso não se concretizar. Essa é a forma mais profunda de assimilação da vulnerabilidade econômica, uma internalização inconsciente que se manifesta através do individualismo, ou através dos mecanismos de corrosão ética e ideológica das bases laborais do grupo, conforme as palavras de Sérgio de Carvalho:

Quando essa força de desagregação é inconsciente e não é tratada ou abordada pelo grupo, ela emerge na forma de um desconforto, uma inquietação, que se manifesta através de intrigas, brigas e desavenças. Quando essa força de desagregação é trazida ao consciente e trabalhada pelo grupo, pode fazer surgir soluções que construam outros caminhos, outras saídas para o mesmo problema e, ao contrário de desagregar, fortalecendo as relações (2014).

A análise do diretor do Latão expõe, ao meu ver, uma percepção do mecanismo invisível através do qual se interligam numa relação de causa e efeito as pressões e os conflitos existentes num grupo. Daí a importância de se buscar uma constante reflexão e observância sobre as forças de desagregação e como o grupo pode 
atuar para desenvolver estratégias criativas que permitam-lhe enfrentá-la. A grande questão desse pensamento de Sérgio de Carvalho é como trazer à tona tais forças e quais ações estratégicas elas podem suscitar. A combinação de repressão com falta de financiamento é a marca da resistência de boa parte das iniciativas grupais no movimento teatral brasileiro. Essas forças represam um desejo de grupalidade que irrompe de tempos em tempos nas inúmeras iniciativas de teatro de grupo surgidas nos anos oitenta, noventa e dois mil, ampliados por modernas leis de fomento. 


\section{REFERENNCIAS}

ABREU, Kil. Experimentação e realidade: grupos e modos de criação teatral no Brasil. In: SAADI, Fátima; GARCIA, Silvana (Org.). Próximo Ato: Questões da Teatralidade Contemporânea. São Paulo: Itaú Cultural, 2008.

ABREU, Márcio. A cara escondida do teatro. In: Subtexto: Revista de Teatro do Galpão do Cine Horto. Grupos de Teatro no Brasil: realidade e diversidade. Ano IV, Nov. 07, Número 4, p. 58-60, Belo Horizonte, 2007.

CABANCHIK, Samuel. Introducciones a la filosofia. Buenos Aires: Ed. Barcelona, Gedisa y Universidad de Buenos Aires; 2000.

CARREIRA, André. Diversidade e renovação do teatro no Brasil. In: Subtexto: Revista de Teatro do Galpão do Cine Horto. Grupos de Teatro no Brasil: realidade e diversidade. Ano IV, Nov.o7, Número 4, p. 9-11, Belo Horizonte, 2007.

DUBATTI, Jorge. Filosofía del Teatro I: Convivio, experiencia, subjetividad. Buenos Aires: Atuel, 2007.

FERNANDES, Sílvia. Grupos de teatro nos anos 70. In: ARAÚJO, Antônio; AZEVEDO, José Fernando Peixoto de; TENDLAU, Maria (orgs.). Próximo Ato: Teatro de Grupo. São Paulo: Itaú Cultural, 2011.

NETO, Gordo. Teatro de Grupo e Grupo de Teatro. In: Subtexto: Revista de Teatro do Galpão do Cine Horto. Grupos de Teatro no Brasil: realidade e diversidade. Ano IV, Nov.07, Número 4, p. 34-35, Belo Horizonte: 2007.

PEIXOTO, Fernando. Teatro de Grupo: significado e necessidade. In: Máscara Revista de Teatro. Ano 1, Número 1, p. 6-7. Ribeirão Preto: 1992.

PICHON-RIVIÈRE, Enrique. Teoria do vínculo. Tradução de Eliane Toscano Zamikhouwsky. 7.ed. São Paulo: Martins Fontes: 2007.

PICON-VALLIN, Béatrice. A propósito do teatro de grupo: ensaio sobre os diferentes sentidos do conceito. In: SAADI, Fátima; GARCIA, Silvana (Org.). Próximo Ato: Questões da Teatralidade Contemporânea. São Paulo: Itaú Cultural, 2008.

TROTTA, Rosyane. Grupos de Teatro no Brasil: convergências e divergências. In: Subtexto: Revista de Teatro do Galpão do Cine Horto. Grupos de Teatro no Brasil: convergências e divergências. Ano V, Dez.o8, Número 5, p. 32-36, Belo Horizonte: 2008. TROTTA, Rosyane. Coletivos Autorais. In: ARAÚJO, Antônio; AZEVEDO, José Fernando Peixoto de; TENDLAU, Maria (orgs.). Próximo Ato: Teatro de Grupo. São Paulo: Itaú Cultural, 2011. 